millennium B.c. to man's earliest occupation of the site, a period of not less than three millennia, possibly more.

\section{Parallels of Habits and Beliefs}

The Frazer Lecture was delivered at the University of Oxford on May 10 by Prof. H. J. Rose, of the University of St. Andrews. The title of the lecture was "Concerning Parallels", and Prof. Rose discussed the legitimacy of the sort of parallels to classical religious phenomena which Frazer uses, leading up to a discussion of polygenetic versus distributionist views in anthropology. His general argument was that the use of parallels between the habits and beliefs of one people and another, while particularly conspicuous in the works of Frazer, is nothing new, being prominent in works published so early as the eighteenth century. It has generally involved recognition of the principle laid down by Bergier (1760) that "partout les hommes se ressemblent". Frequently there has gone with it a shallow conception of human evolution, tacitly assuming that the resemblance between different peoples at approximately the same stage of culture is so close as to amount to identity, and also that the stages of culture can be dated by merely placing first in time those which appear simplest and most brutish. This being the result of false reasoning and the neglect of elementary philosophic principles, has led to unsound results. In consequence, the attempts of the so-called historical school, of which Graebner, Pinard de la Boullaye and W. Schmidt are outstanding representatives, to establish objective criteria of dating and a strictly scientific method of handling the facts must be welcomed, whether the results they have so far achieved are acceptable or not. The criteria are, however, open to serious objection. Examples can easily be found of usages from peoples, wholly unconnected ethnologically, illustrating each other in a most welcome fashion, the common humanity of the minds of both being more important than any specific difference. The most fruitful activity of an anthropologist is rather psychological than historical or geographical, although these aspects should not be neglected; and to misunderstand the motive of an action may result in failure to place it even in its right historical context.

\section{Royal Cornwall Polytechnic Society}

THE hundredth annual report of the Royal Cornwall Polytechnic Society is of unusual interest. It contains among other matter accounts of the hundredth annual meeting held at Falmouth on February 21, 1933, and of the centenary summer meeting held on July 18-21. At the opening session of the latter the president, Viscount Clifden, occupied the chair and a series of addresses of congratulation was presented on behalf of the Royal Society, Royal Institution and other bodies. During the four days there were excursions and visits to works, and five addresses were delivered by well-known men of science. Sir Richard Gregory's address dealt with "Science Applied to Industry"; Sir John Cadman spoke on "Science, One and All", making special reference to the operations in the oil-fields of Persia and Iraq; Sir Napier Shaw on "Unofficial Meteorology" ; Dr. G. C. Simpson on "Modern Methods of Weather Forecasting" ; and Prof. S. J. Truscott on "Problems of Mining at Great Depths". These addresses are printed in full in the report, and that by Sir Napier Shaw is accompanied by an interesting series of photographs.

Frequent references were made at the meeting to some of the pioneers in Cormish industry, and one of the visits was to the Safety Fuse Works of Messrs. Bickford-Smith and Co. Ltd., Tuckingmill. The invention of the safety fuse was due to William Bickford, who had been struck by the frequency of accidents in mines and the number of men in Cornwall totally or partially blinded through them. Appended to the report is an account of the work of the Falmouth Observatory, which has actively co-operated with the Meteorological Office since 1868. This was referred to in the address of congratulation from the Meteorological Committee signed by Sir Philip Sassoon, Under-Secretary of State for Air. Recently the old observatory tower, where the observations were made from 1868 until 1885, has had a commemoration tablet fixed to it.

\section{Photography of Sound}

"Some Photographic Aspects of Sound Recording" was the subject of the Sir Henry Trueman Wood Memorial Lecture, which was given by Dr. C. E. Kenneth Mees, of the Eastman Kodak Company, at the Royal Society of Arts on May 16. Dr. Mees stated that the introduction of sound recording has influenced every section of the motion picture industry, from the nature of the original material selected for the presentation to the architectural design of the motion picture theatre itself. Two methods of sound recording are in general use, leading in one case to records in which the density of the photographic deposit varies, and, in the other, to records in which the area occupied by the photographic deposit varies. Reproduction depends on three qualities, loudness, frequency of pitch and wave form quality or timbre. The intensity range is limited primarily by the ground noise, which is chiefly due to physical defects in the films, such as scratches and dirt, although even in a perfectly clean film there is a very small amount of ground noise due to the granular structure of the silver deposit. By the use of special apparatus it is now possible to reduce ground noise considerably. The reproduction of high frequencies is dependent upon the resolving power of the photographic film. Special experimental apparatus has been designed to analyse the wave form and quality of the reproduction. "Improvements in the reproduction of sound by photographic means," Dr. Mees concluded, "will depend, in the future as in the past, on intensive scientific research in relation to sound, electricity, and photography."

\section{Historical Physical Apparatus}

Sir Henry Lyons, formerly director of the Science Museum, delivered his presidential address to the 